\title{
The Entire History of You: as ilusões da memória técnica ou a arte do esquecimento
}

\author{
Juracy Oliveira ${ }^{1}$ \\ Sergiano Silva ${ }^{2}$
}

\begin{abstract}
Resumo: Nossa época é marcada por uma obsessão pela gravação e pelo arquivamento da nossa experiência através do uso das tecnologias. Tal constatação nos leva a um dos futuros possíveis no tocante à memória técnica, leia-se: uma realidade na qual tornou-se comum o uso de próteses mnemônicas que armazenam todos os dados da percepção, propiciando a rememoração irrestrita do vivido. Esta é precisamente a premissa do episódio Toda a sua história da série Black Mirror. A partir da sua análise, o presente artigo almeja esmiuçar as implicações sociais e culturais da tecnologia, sobretudo os seus usos e abusos, tomando como base teórica as discussões em torno da memória viva, da cultura da memória, do arquivo, da memorização tecnológica e, também, do esquecimento.
\end{abstract}

Palavras-chave: Arquivo; Black Mirror; Cultura da memória; Memória técnica; Esquecimento.

Abstract: Our time has, as one of its main marks, an obsession concerning the recording as well as the archiving of our experience through technology. This assertion leads us to one of the possible futures regarding technical memory, namely: one reality in which mnemonic prostheses that store all the perception data are widely used, providing the unrestricted remembrance of the past. It is precisely the premise of Black Mirror's episode The Entire History of You. The present paper aims at analyzing the social and cultural implications of the mnemonic technology employed in this episode, especially its uses and abuses, having as theoretical background the discussions about natural memory, memory culture, archive, technological memorization and forgetting.

Keywords: Archive; Black Mirror; Memory culture; Technical memory; Forgetting.

1 Doutoranda em Tecnologias da Comunicação e Cultura (PPGCOM/UERJ) e bolsista da Fundação Carlos Chagas Filho de Amparo à Pesquisa do Estado do Rio de Janeiro (FAPERJ).E-mail: juracy oliveira@hotmail.com

2 Doutor em História Social da Cultura pelo Programa de Pós-Graduação em História da Pontifícia Universidade Católica do Rio de Janeiro (PUC-RJ) e bolsista CNPq. E-mail: sergiano silva@hotmail.com 
Sabía las formas de las nubes australes del amanecer del treinta de abril de mil ochocientos ochenta y dos y podía comparar la sen el recuerdo con las vetas de un libro en pasta española que sólo había mirado una vez y con las líneas de la espuma que un remo levantó e nel Río Negro la víspera de la acción del Quebracho.

Jorge Luis Borges

Sendo um dos mais memoráveis personagens da obra de Borges (1981, p. 128), Funes é conhecido pela prodigiosa memória adquirida após uma queda de cavalo. Logo após o acidente, o memorioso torna-se dotado não apenas de uma percepção minuciosa e precisa das coisas do mundo nos seus sucessivos estados, ao ponto de recordar cada folha de cada árvore de cada monte, tivessem sido elas percebidas ou imaginadas, mas, sobretudo, de uma rica memória que evoca lembranças igualmente vivas. Desse modo, Funes poderia reconstruir detalhadamente um dia inteiro se assim o desejasse - ainda que isso lhe tomasse outro dia inteiro.

A memória do personagem de Borges funciona como um arquivo que acumula as exatas diferenças entre os estados das coisas ao seu redor. Ao capturar por meio da percepção os detalhes imediatos do mundo, ele consegue formar uma espécie de linha do tempo que integra a totalidade do próprio devir nas suas diferenças, sem falhas ou interrupções; assim, ele produz um banco de dados integral do vivido que permite uma rememoração completa do passado. No entanto, Funes não podia abstrair ou generalizar tais diferenças, ou seja, não podia reelaborar as próprias lembranças prodigiosas que detinha. Enfim, ele não podia esquecer para melhor lembrar, em termos qualitativos e não apenas quantitativos.

Mesmo que nos assombre essa ideia de uma memória que nada esqueceria (RICOEUR, 2007, p. 424), ironicamente, a memória cultural do nosso tempo tem se parecido cada vez mais com aquela descrita no conto borgesiano, isto se considerarmos que a sua expressão maior são os bancos de dados que constituem as redes sócio-técnicas digitais que armazenam os micro-arquivos presenteístas da nossa experiência cotidiana. Estes arquivos universais contemporâneos registram, em larga escala, cada dado como que depositando os nossos fragmentos de recordação e catalogando as nossas vivências. É justamente nesses locais de infinitude humanamente concebível que se torna mais nítida a nossa atual obsessão pela memória e seu arquivamento.

Assim, Andreas Huyssen (2000, p. 14) identifica que está em voga na contemporaneidade uma cultura da memória que promove o que ele denomina automusealização, que pode ser entendida como o processo de gravação e arquivamento das próprias experiências por meio da técnica. Naturalmente, essa monumentalização da 
memória expressa-se através do uso das novas tecnologias. Estas organizam e racionalizam as lembranças como que para negar, reduzir ou mesmo anular a própria possibilidade de extravio dos dados.

Ou seja, a obsessão desenfreada pelo registro e pela retomada do passado tem como estopim o medo decorrente do esquecimento, o duplo da lembrança. Em última instância, como pensa Fausto Colombo (1991, p. 96), "o sonho, nem tão disfarçado, é portanto o de uma imediata e perfeita translação do mundo para uma memória inalterável e estanque no que diz respeito às perdas causadas pelo tempo e pelo esquecimento”. Nessa economia da memória infinita, almeja-se uma memória técnica total, uma prótese mnêmica, que arquive todas as informações afluentes à percepção e as torne acessíveis para posterior rememoração.

Posto que a dinâmica atual das mídias, embora operando nitidamente sob temporalidades maquínicas, (felizmente) ainda não alcançou o estágio dessa memória espectral, cabe aqui nos voltarmos para o futuro, ou melhor, para os "futuros possíveis" que as tecnologias podem nos proporcionar em termos de registro e recuperação mnemônica. Nesse caso, tomamos como objeto de análise um episódio da cultuada série britânica Black Mirror [1] que lida justamente com uma memória técnica totalizante. Nosso objetivo consiste, mais especificamente, em esmiuçar a tecnologia empregada, além de seus usos e desusos, tomando como base teórica as discussões em torno da memória natural, da cultura da memória, do arquivo, da memorização tecnológica e, também, do esquecimento.

\section{Memória, cultura da memória e archivefever}

A memória, como o conhecimento afetivo e existencial de um passado carregado por indivíduos e grupos, um elo do vivido no presente que se materializa nos espaços, nos gestos, nas imagens e nos objetos, como nos propõe Pierre Nora (1993, p. o9), é sempre um fenômeno múltiplo, atual e em permanente evolução, abrindo-se não apenas à dialética lembrança/esquecimento, mas também às sucessivas manipulações, fabulações e revitalizações. Ademais, "porque é afetiva e mágica, a memória não se acomoda a detalhes que a confortam; ela se alimenta de lembranças vagas, telescópicas, globais ou flutuantes, particulares ou simbólicas, sensível a todas as transferências, cenas, censura ou projeções” (Ibidem).

O caráter fragmentário e descontínuo da memória impõe a necessidade de uma organização narrativa desses pedaços de lembranças do passado. Trata-se, por- 
tanto, de um fenômeno construído, consciente e inconscientemente, na medida em que "a memória individual grava, recalca, exclui, relembra" (POLLAK, 1992, p. 204) como forma de conferir certa unidade, coerência e continuidade ao próprio sentimento de identidade. Isto porque, argumenta Pollak (Ibidem), a construção da identidade é formada pela amálgama entre a unidade física, a coerência interna da história de vida e a continuidade no tempo. Dessa forma, a elaboração da memória torna-se vital nessa permanente manutenção e reconstrução de si - portanto, a constância retrospectiva da identidade, partindo da coesa relação entre passado e presente, lança-se também prospectivamente.

A tais pensamentos sobre essa memória viva das lembranças do passado devemos sobrepor o caráter tecnologicamente mediado da sua experiência na atualidade. Logo porque, como indica Huyssen (2000, p. 09), se a modernidade que marcou o início do século XX voltava-se, sobretudo, para o futuro, a modernidade avançada em voga, principalmente a partir da década de 1980, período que marca o início da ascensão das tecnologias binárias, promove uma espécie de retorno nostálgico ao passado; a memória se torna, então, uma obsessão cultural nas sociedades ocidentais. Não à toa, além da automusealização dos sujeitos, há um boom de modas ditas retro e também de comercialização massiva da nostalgia, dentre outras recorrências que só têm inflacionado a moeda da memória e do passado dentro da indústria cultural.

Hans Ulrich Gumbrecht (2004, p. 94) sugere que há aí um desejo pela presentificação de mundos passados e realidades anteriores a partir de técnicas que enfatizam, sobretudo, a sua dimensão espacial, produzindo a impressão de que estes se tornam novamente tangíveis. Essa onda nostálgica de rememoração, com seu anseio por presença, existe no espaço de simultaneidade do presente, promovendo a reprodução do passado e seus produtos - desde antigas gravações e edições fac-símile de obras impressas até a reconstrução e a ambientação histórica fidedignas de romances e filmes.

Por conseguinte, esse retorno ao passado idealizado talvez indique uma nova forma de apreensão do próprio futuro, não mais encarado pela ótica de uma esperança progressista, mas como aquilo que anuncia iminentes catástrofes. Além disso, a fixação que marca a cultura da memória insinua

uma lenta mas palpável transformação da temporalidade nas nossas vidas, provocada pela complexa interseção de mudança tecnológica, mídia de massa e novos padrões de consumo, trabalho e mobilidade global. Pode haver, de fato, boas razões para pensar que a força da rememoração tem igualmente uma dimensão mais benéfica e produtiva. No entanto, muito disso é o deslocamento de um medo do futuro nas nossas preocupações com a memória e, por mais dúbia que hoje nos pareça a afirmação de 
que somos capazes de aprender com a história, a cultura da memória preenche uma função importante nas transformações atuais da experiência temporal, no rastro do impacto da nova mídia na percepção e na sensibilidade humanas (HUYSSEN, 2000, p. 25-26).

Adicionalmente, essa nova experiência de tempo intersecciona-se não apenas com o advento tecnológico, mas com um novo regime de memória que promove outros mecanismos, agora técnicos, de memorização ao passo que estabelece uma relação com o passado que enfatiza do psicológico ao histórico, do individual ao social, do subjetivo ao transitivo, da rememoração à repetição (NORA, 1993, p. 18). São precisamente essas mudanças que, embora anteriores à ascensão das novas tecnologias, são enfatizadas por elas, parecem promover a morte do narrador benjaminiano como a representação encarnada de uma tradição coletiva que desaparece em prol de uma psicologização de memórias individuais fragmentadas que falam de si, mas esquecem do todo, fenômeno esse sintetizado no gênero literário romance (BENJAMIN, 1977, p. 442). Tal como no romance, a memória comunitária tende a segregar-se, a restringir-se ao indivíduo isolado perdendo todo o seu caráter didático de exemplificação; ambos flertam, não por acaso, com o ilimitado, segundo Walter Benjamin: "na apresentação da vida humana, escrever um romance significa levar o incomensurável (Inkommensurable) ao extremo" (Ibidem, p. 443).

Diante desse novo modus operandi da memória cultural, recalca-se a possibilidade mesma do esquecimento mediante o arquivamento generalizado da experiência. Nora é preciso ao afirmar que

nenhuma época foi tão voluntariamente produtora de arquivos como a nossa, não somente pelo volume que a sociedade moderna espontaneamente produz, não somente pelos meios técnicos de reprodução e de conservação de que dispõe, mas pela superstição e pelo respeito ao vestígio. À medida em que desaparece a memória tradicional, nós nos sentimos obrigados a acumular religiosamente vestígios, testemunhos, documentos, imagens, discursos, sinais visíveis do que foi, como se esse dossiê cada vez mais prolífero devesse se tornar prova em não se sabe que tribunal da história. $O$ sagrado investiu-se no vestígio que é sua negação. Daí a inibição em destruir, a constituição de tudo em arquivos, a dilatação indiferenciada do campo do memorável, o inchaço hipertrófico da função da memória, ligada ao próprio sentimento de sua perda e o esforço correlato de todas as instituições de memória (NORA, 1993, p. 15).

E, assim, ao conservarmos todos os indícios da memória e do vivido, mesmo aqueles desprovidos de qualquer utilidade prática, o arquivo existe tautologicamente apenas pelo próprio acúmulo irrestrito de lembranças [2]. Produzir arquivos se torna, por fim, o próprio imperativo de nossa época.

Vale notar que esse archivefever, oriundo da evolução tecnológica, ambicio- 
na, no limite, conservar a própria forma-tempo ao pretender-se exaustivamente completo, encerrando no seu interior todo um passado passível de presentificação imediata (COLOMBO, 1991, p. 64). Nesse caso, a acumulação em curso nesse gigantesco estoque material de memória registra aquilo que, nos sendo impossível lembrar por meios naturais, relega às tecnologias a tarefa de memorizar. Desse modo, "para a consciência arquivística contemporânea os arquivos suprem as falibilidades do sujeito humano, substituem-no, e no limite transcendem-lhe" (Ibidem, p. 110-111).

Especulando um pouco sobre a transcendência última da memória humana, esta talvez pudesse ser uma prótese que estendesse a nossa faculdade mnêmica, ou melhor, registrasse tudo aquilo que chega à nossa percepção e gerasse um arquivo total de todas as nossas experiências tal qual ocorreram. Em linhas gerais, esta é precisamente a tecnologia apresentada no episódio Toda a sua história (The Entire History of You, Brian Welsh, 2011) da série Black Mirror em que, por meio de uma memória técnica pós-humana, assistimos a obsessão mnemônica chegando ao seu ponto máximo.

Lembrando que a materialidade do arquivo arquivante não apenas registra, mas também produz o evento, como nos conta Derrida (2001, p. 29), a técnica não jaz neutra durante o processo de memorização e de rememoração. Neste sentido, nos interessa discutir justamente as implicações dessa memória no tocante aos seus usos e seus desusos.

\section{A memória técnica em The Entire History of You}

O episódio tem como enredo uma história clássica sobre ciúmes e infidelidade que nada teria de memorável se não fosse o protagonismo assumido pela tecnologia de memória Willow Grain, que basicamente conduz todos os reveses da narrativa. Passando-se numa realidade alternativa, quiçá o nosso futuro, vemos que o uso de um microchip implantado na mentetornou-se culturalmente hegemônico. Ele grava todas as nossas percepções visuais e auditivas, arquivando-as como lembranças que podem ser repetidas indefinidamente.

Considerando que nosso interesse é menos no aspecto narrativo do episódio e mais na tecnologia em si, em linhas gerais, a ação pode ser resumida da seguinte maneira: Liam Foxwell, durante um jantar na casa de amigos de sua esposa, Ffion, passa a desconfiar da relação dela com um colega de longa data, Jonas. Liam, ao esmiuçar e analisar obsessivamente as suas próprias memórias, as de Jonas e as de Ffion, por fim descobre que a esposa de fato o havia traído com o colega, que pode também ser o pai 
biológico da filha do casal.

\section{A tecnologia}

O Willow Grain consiste num implante colocado atrás da orelha que, exercendo a função de uma prótese mnêmica, grava tudo aquilo que é feito, visto e escutado pelo seu portador, criando uma espécie de backup totalizante da memória natural. A partir de um dispositivo manual cada usuário pode acessar e manipular o seu "espectro de memória completo" (full spectrum memory), isto é, a timeline que dispõe as imagens audiovisuais das lembranças gravadas para rememoração (processo chamado de redo, ou seja, refazer). Essa memória granular possui uma série de ferramentas que permitem a manipulação técnica das lembranças. Ao longo do episódio são apresentados ou sugeridos recursos, tais como: voltar e avançar o vídeo da lembrança ou mesmo aumentar a sua velocidade, dar zoom em pontos específicos das imagens, deletar [3] e editar memórias, fazer leitura labial de determinados trechos inaudíveis, buscar as memórias linearmente no tempo ou procurar pelas memórias com pessoas específicas, dentre outras funções.

Ao "arquivar imediatamente o presente e apresentar (presentificar) o passado justamente como dimensões temporais” (COLOMBO, 1991, p. 63), essa prótese de memória se torna uma representação do próprio tempo - posto que, em certa medida, o produz, o armazena e o manipula, estabelecendo uma dialética entre presença, ausência e distância (RICOEUR, 2007, p. 435), isto é, entre um antes que já foi, e que rememoro, e um agora sobre o qual atuo. Nesse caso, a reflexão filosófica de Henri Bergson em Matéria e memória (1999) se revela oportuna para pensar a memória sob o viés da ideia de duração.

O conceito bergsoniano indica uma progressão contínua do passado sobre o presente, o que promove quase uma indiferenciação entre essas duas durações, na medida em que toda percepção do presente já constitui um passado imediato. O futuro, por sua vez, é também contaminado pela dimensão do presente, visto que cada agora é também futuro imediato (BERGSON, 1999, p. 161). Em suma, podemos dizer que o prolongamento do passado nas outras durações, como o pano de fundo que compõe todas as lembranças de uma vida, é útil pois ajuda a "compreender o presente e a prever o porvir" (Ibidem, p. 61).

Por conseguinte, ao pensarmos o nosso presente a partir do passado, as lembranças que se encontram em estágio de latência, ou seja, num estado virtual, são 
atualizadas, literalmente presentificadas, durante o processo de rememoração, ou melhor, de evocação dessas imagens do passado. Assim, como nos informa Deleuze (1966, p. 59), leitor de Bergson, "sob o apelo do presente, as lembranças já não têm mais a ineficácia, a impassibilidade que as caracterizavam como lembranças puras; elas se tornam imagens-lembranças (images-souvenirs), capazes de serem 'evocadas'. Elas se atualizam ou se encarnam". Vale lembrar que essa adaptação e utilização do passado em função do presente é proveniente da atenção dispensada ao momento de agora, que é o próprio lugar da experiência.

Em Bergson (1999), essa experiência é captada pela memória no instante de sua ação e as lembranças surgem conjuntamente com a percepção oriunda dela, ou mais precisamente, o passado passa a existir como duração na medida que a percepção se desprende da experiência. O mesmo ocorre na memória técnica, já que os dados provenientes do Willow Grain são também oriundos das percepções do mundo vivido e registradas em seus mínimos detalhes, constituindo um arquivo de armazenamento, catalogação e reprodução das memórias do passado, cuja lógica memorial se baseia na exaustividade da acumulação irrestrita do acontecido - indo desde o momento atual, o passado quase presente, até o passado propriamente dito. E como protagonista das próprias memórias, naturalmente, o vivido é gravado numa perspectiva de primeira pessoa - aqui, olhos e ouvidos assumem o registro da experiência que será posteriormente arquivada - e a cada acontecimento da vida cotidiana é atribuído uma data, uma hora e um lugar. Assim, cada um desses arquivos-acontecimentos, como signos mnemônicos, representam "não um evento, mas o átimo no qual este se deu" (COLOMBO, 1991, p. 62).

Em termos bergsonianos, enquanto o arquivamento virtualiza a lembrança do vivido, a sua evocação promove uma atualização desta; por conseguinte, na supracitada tecnologia, as imagens-lembranças são encarnadas, por assim dizer, mediante a projeção da interface do arquivo de memórias a partir dos olhos. Nesse peculiar modo de projeção é possível materializar a imagem no espaço, desse modo apenas o usuário as visualiza, ou também numa tela, permitindo que a lembrança seja compartilhada com outras pessoas. Assim, à função do olhar de apreender e registrar o mundo é acrescida outra, a de projetar as memórias para fora do corpo em forma de imagem em movimento.

Figura 1 - a interface da timeline do WillowGrain 


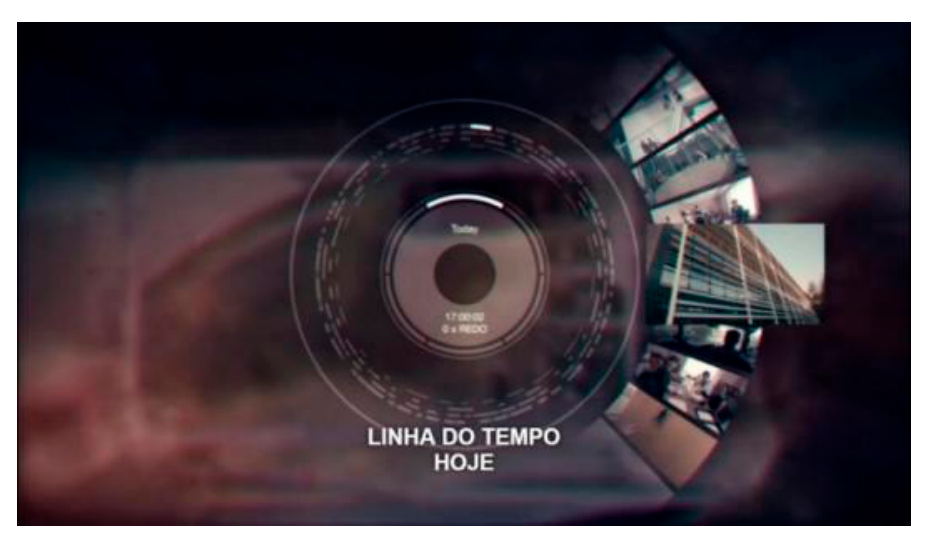

Fausto Colombo (1991, p. 17-19) propõe como categorias principais de memorização técnica do tempo presente a gravação, o arquivamento e o arquivamento da gravação: a gravação seria o registro do acontecimento num suporte por meio de uma imagem audiovisual; já o arquivamento seria a tradução do evento em informação digital, transformando em códigos binários cada dado do mundo. Por último, o arquivamento da gravação consiste na materialização da imagem-recordação num signo arquivístico localizável no sistema. Na tecnologia em análise, como já foi dito, olhos e ouvidos servem à função de gravação das percepções da experiência do mundo, que são devidamente arquivadas na prótese mnêmica, um banco de dados buscável das nossas memórias. Quanto ao arquivamento da gravação, trata-se aqui de todos os ícones arquivísticos, passíveis de serem selecionados e rememorados, que compõem a timeline circular do Willow Grain. Nela são mostrados, em ordem temporal, os vários acontecimentos de cada dia, devidamente delimitados com margens precisas, e constituindo-se como signos para rememoração (Figura 1).

Assim, se a memória humana [4] pressupõe essa seletividade no registro e no arquivamento da experiência, a suposta superioridade da memória técnica consiste na captação fiel e total na reprodução exata do vivido, de forma que a lembrança perde, em certa medida, o seu caráter representacional ao exibir o dado bruto da percepção trata-se de um hiper-real artificial do passado que almeja refazer a própria textura da vida na sua rememoração. A totalidade da memória apreendida nesse arquivo dispõe as lembranças como excertos da história de vida do usuário, promovendo um olhar retrospectivo sobre a narrativa vivencial e a trajetória de cada um. E ainda que sejam imagens espectrais do passado, a princípio, elas parecem conseguir usurpar da memória natural a coloração afetiva que lhes caracteriza.

\section{Os usos}


Naturalmente, não é difícil supor que o uso de um arquivo mnemônico total como o Willow Grain, que registra toda a intensidade do vivido e o torna passível de evocação integral, promoveria o deslocamento no modo de se relacionar com a própria memória pessoal. Se anteriormente a rememoração lidava com as lembranças de experiências singulares, agora, pela amplitude do registro e do arquivo, a rememoração técnica retém e disponibiliza, invariavelmente, tudo aquilo que tenha passado pelo filtro da percepção durante uma vida. Ou seja, a lembrança se torna "passado completo em sua reconstituição mais minuciosa. É uma memória registradora, que delega ao arquivo o cuidado de se lembrar por ela" (NORA, 1993, p. 15).

Uma das implicações desse acesso total aos arquivos de vida de cada um é que, mesmo as memórias sendo pessoais e intransferíveis, os usuários dessa tecnologia voluntariamente compartilham coletivamente seus fragmentos. Portanto, não se trata de expor todas as lembranças, mas sim aquelas selecionadas cuidadosamente, isto é, apenas aquilo que deseja exibir diante de uma audiência também seleta. Vale lembrar que essa dinâmica entre o mostrado e o escondido, a partir do uso de técnicas de gerenciamento de impressão, é essencial para manter a encenação do self perante o seu público, como propõe o modelo dramatúrgico de interação social de ErvingGoffman (Cf. 1990).

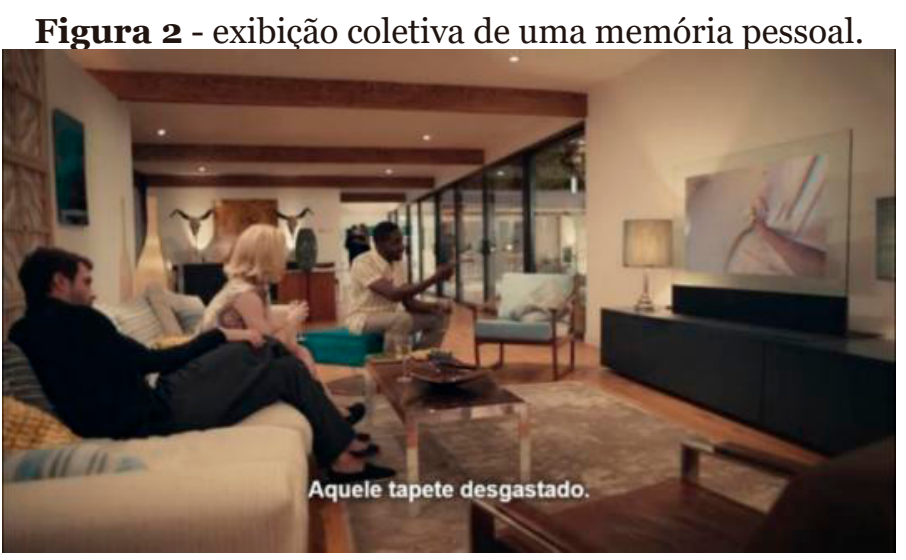

Ao longo do episódio há diversas cenas nas quais a memória é tornada coletiva, isto porque o usuário projeta as lembranças numa tela de modo a mostrá-las e analisá-las com outras pessoas, em geral, íntimas (Figura 2). Fazendo uma aproximação com a memória coletiva proposta por Maurice Halbwachs (2006), a princípio, podemos afirmar que nessa realidade as nossas experiências, e consequentemente, memórias, ainda estão invariavelmente ligadas a grupos específicos, de forma que as memórias individuais perpassam as coletivas, que compõem o todo do grupo. Nesse 
caso, cada memória individual não é senão um recorte, um ponto de vista da memória coletiva, que partilha tais lembranças técnicas.

No entanto, o caráter coletivo que se sobressai nessa memória não é apenas o de Halbwachs. Embora seja possível compartilhar com o outro uma lembrança conjunta sob um ponto de vista, há também a possibilidade de compartilhá-la não porque dividimos aquela experiência, mas apenas porque assim desejamos fazê-lo; ou seja, essa memória é coletiva porque a lembrança individual é partilhada deliberadamente, deixando de se restringir ao grupo que dela participou. Talvez aqui, ao invés de uma memória coletiva, possamos propor uma memória coletivizada, mediatizada pelo indivíduo.

Quanto à tal prática de coletivização, que se tornou comum nesse contexto cultural de memória técnica, sabe-se que o compartilhamento de memórias com outrem sempre foi feito, seja por meio do relato oral e escrito ou de imagens técnicas como a fotografia [5] e o vídeo. A diferença aqui é que a lembrança é experienciada pelo receptor não apenas como um mero fragmento parcial do acontecimento, mas, pelo contrário, como o dado concreto do que de fato aconteceu, desbotando, portanto, o caráter narrativo, imaginativo e simbólico da memória. Isto porque, como nos aponta Benjamin no ensaio sobre Baudelaire, "a constante prontidão da lembrança voluntária”, promovida pelas técnicas de reprodução, "reduz o campo da imaginação" (BENJAMIN, 1974, p. 645).

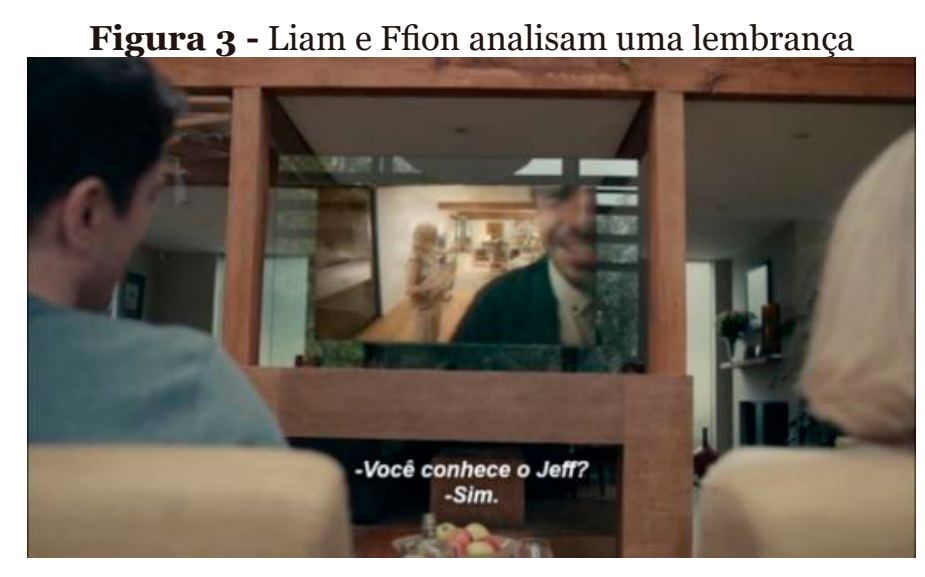

Outro aspecto resultante dessa exteriorização da memória de uma vida é que as lembranças parecem ser retomadas de forma bem mais objetiva e até mesmo analítica. Isto fica claro durante o episódio por meio do personagem principal, Liam Foxwell, que analisa fria e imparcialmente as próprias memórias até descobrir a infidelidade da sua esposa (Figura 3). E ainda que essa rememoração implique em reelabo- 
ração e em ressignificação do acontecido, tal qual na memória natural, isso ocorre por meio de uma análise exaustiva do todo acumulado naquela memória técnica, inclusive fazendo uso de todas as ferramentas disponíveis, denotando certo distanciamento e impessoalização com relação às próprias lembranças.

Tomando a si mesmo e suas lembranças como objeto, o sujeito dessa memória arquivística vê entrecruzarem-se "a dimensão intelectual e a dimensão afetiva do esforço de recordação" (RICOEUR, 2007, p. 48), destacando-se, sobretudo, a sua racionalização, talvez até em detrimento do seu aspecto emotivo. Isto porque a confrontação de todo o passado vivido permite uma análise obsessiva das lembranças de modo que a função prática dessa memória se torna a investigação de todos os seus rastros.

Com efeito, a rememoração obsessiva e detalhista propiciada pela técnica promove o apagamento da dimensão útil do passado sobre o presente; o agora deixa de existir como duração em prol da recordação sobrevalorizada das lembranças, vive-se no passado sem que isso traga qualquer proveito para a situação atual. Uma consciência como essa, desligada da ação presente e voltada apenas para a totalidade do seu passado, é tratada por Bergson (1999, p. 181-182) como uma existência do sonho, uma memória contemplativa que apreende "a multidão infinita dos detalhes de sua história passada" sem jamais sair do particular, "dando à cada imagem sua data no tempo e seu lugar no espaço”, vendo apenas o singular e não as relações entre as lembranças. Esta é, precisamente, a maneira como Liam experiencia a sua memória ao longo de todo o episódio, até o seu previsível desenlace.

\section{Os desusos}

Sigmund Freud compreendia o esquecimento como um ato falho característico das patologias cotidianas; não lembrar indicaria uma vontade hostil do consciente em manter certa ação desvinculada de uma realidade sofrível. Isso ocorre de acordo com o princípio do prazer, ou seja, "a aversão da memória a se lembrar de algo associado a sentimentos de desprazer (Unlustempfindungen), e que se renovaria com a reprodução desse sentimento" (FREUD, 1969, p. 93). O aparelho psíquico tenta evitar ao máximo as indicações de desprazer que alguns eventos implicariam, daí que essa fuga constante seria o motivo fundamental para o esquecimento.

Já a memória técnica, como aquela que nada esquece, por si mesma promove apenas a obsessão pelo registro total da experiência, mas não pela rememoração das suas lembranças. No entanto, é notável que a inflação do arquivo mnêmico pessoal 
propicia uma relação doentia com a memória, tal qual a de Liam. No caso dele, a invasão contínua do passado no tempo de agora reprime os próprios impulsos do presente, tornando-o cativo do já vivido simplesmente porque não pode esquecê-lo.

Na ausência mesmo desse filtro de "utilidade" do passado, as lembranças inflacionam-se e tomam o presente de assalto, largam a sua duração passada para entrar numa que não é sua de direito. Essa memória hiperdimensionada que destrói a temporalidade do presente porque sempre busca as imagens do passado deixa de ser útil ao agora e existe em prol da sua dolorosa rememoração e presentificação. O tempo pessoal do presente é trocado, então, pelo tempo do arquivo, o tempo do passado na sua pluralidade de memórias.

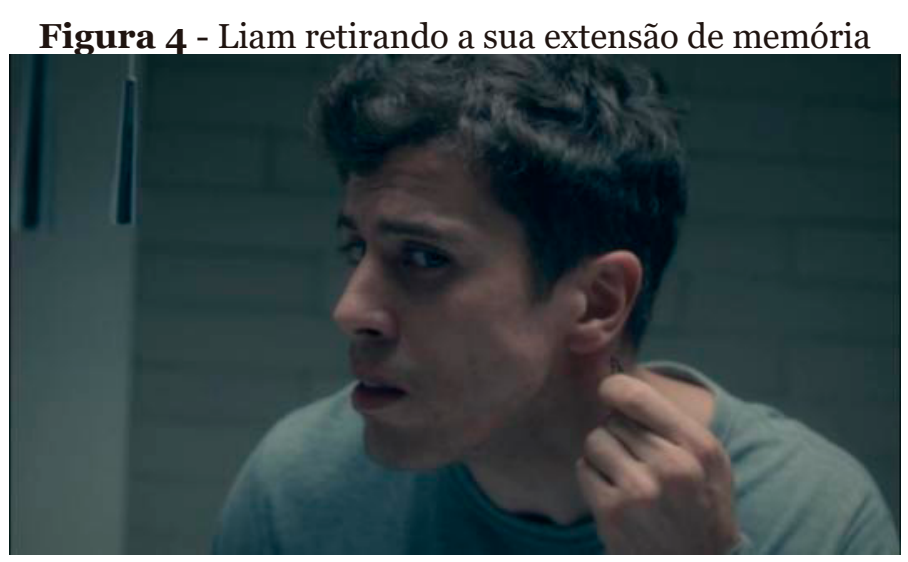

Esse espectro de memória mantém o loop de lembranças como uma imagem refletida num espelho dos enganos. Desse modo, o "retorno do passado", diz Beatriz Sarlo (2007, p. 09), "nem sempre é um momento libertador da lembrança, mas um advento, uma captura do presente”, porque nos acomete até quando não requerido e nos obriga a persegui-lo. Liam, prisioneiro do próprio passado, é atormentado por duas lembranças fantasmáticas: primeiro, a infidelidade da esposa, e segundo, ao final do episódio, as lembranças felizes de Ffion e de sua filha - que contrastam com a solidão na qual se encontra o personagem, e sugerindo mesmo o divórcio do casal após todas as revelações. Como solução extremada para sanar essa memória obsessiva, ele decide retirar o implante Willow Grain (Figura 4) e, ao fazê-lo, surgem flashes das suas lembranças da esposa como se estas estivessem sendo todas esquecidas com a própria retirada da prótese mnêmica, num ato de divórcio também das memórias.

Por conseguinte, o desfecho do episódio acaba por promover a faculdade do esquecimento como aquilo que é capaz "de cancelar ou de fazer extraviar o que foi memorizado" (COLOMBO, 1991, p. 97), apagando definitivamente os dados arquivados na extensão de memória. Mas Liam vai mais longe ao retirar o próprio recurso mne- 
mônico e negar o uso dessa memória técnica, seu gesto consiste mesmo num elogio ao esquecimento diante de uma memória obsessiva que tudo registra e recupera e que provoca desprazer. Nesses termos, esquecer não é só preciso, é necessário, como uma instância fundamental para pensar também o memorável, principalmente, tendo em vista que "o esquecimento pode estar tão estreitamente confundido com a memória, que pode ser considerado como uma de suas condições” (RICOEUR, 2007, p. 435).

Trata-se aqui de um esquecimento útil que retorna a memória à uma rememoração produtiva (HUYSSEN, 2000, p. 35), posto que a memória técnica é retirada mas permanece a memória viva, natural, humana, pautada na memorização subjetiva, lacunar e até fabulativa. Esse esquecimento técnico, por assim dizer, pode redimensionar a distribuição entre passado, presente e futuro, promovendo não apenas a dimensão retrospectiva da experiência como rememoração, mas, sobretudo, a prospectiva.

\section{Considerações finais}

A gravação automática da memória cultural que toma conta da contemporaneidade transforma a própria ideia de memória, na medida que novos meios e novas formas de armazenamento lhe sugerem outras funções. Assim, "numa época em que, no despertar da revolução da informação e numa sempre crescente compressão do espaço-tempo, a relação entre passado, presente e futuro está sendo transformada para além do reconhecimento" (HUYSSEN, 2000, p. 36, as mídias digitais parecem deter na atualidade o poder de absorver e controlar os meandros entre a nossa memória e o seu esquecimento.

É notável que a ecologia midiática atual promove uma experiência de memória que é intrinsecamente mediatizada, como sugere Andrew Hoskins (2015, p. 15), isto porque o paradigma conectivo vigente, diante da pervasividade intrínseca ao ambiente digital, passa a digitalizar o passado e o presente continuamente de modo a (re) produzir um grande volume de rastros de memória como um registro mnêmico que entrelaça-se com o de outrem nos enredamentos sociais da rede técnica. Tal medialidade, que consiste em tornar a memória um dado gerenciável, termina por exercer uma espécie de controle burocrático ao recolher em seu arquivo todos os traços do self. Estes, com alguma frequência, são regurgitados pela própria rede como fantasmas do passado que retornam para nos assombrar, sendo um exemplo claro disto a ferramenta Lembranças do site de rede social Facebook. Toda a memória potencial recolhida na plataforma (ou melhor, o conteúdo gerado pelo usuário: publicações, fotos, aconteci- 
mentos, aniversários e toda sorte de datas e dados) emerge nas recordações daquele dia em específico talvez para evidenciar não apenas a gestão tecnológica da memória em si, mas, principalmente, do arquivamento doself.

É a capacidade de registro no tempo, leia-se, o ato de agregar, recuperar e exibir as nossas memórias digitais, que promove paralelos entre a mais ampla memória técnica de nossa época, as mídias sociais, e a memória arquivística total que permeia The Entire History of You como uma fábula distópica. O episódio funciona como um alerta quanto a um futuro não apenas possível, mas provável. Dessa forma, problematiza-se a memória atual, que tem como prerrogativa apenas o acúmulo irrestrito, como uma não-memória, visto que a ênfase na infinitude formal desse arquivamento talvez esvazie de sentido os seus registros, cuja importância é desqualificada justamente pela sua incomensurabilidade. Eis o nosso mal de arquivo.

Diante do excesso de memorização técnica que permeia a nossa cultura, a moral final do episódio é mesmo uma celebração da arte do esquecimento através do não-registro de todos os episódios da vida, o que valorizaria a duração do presente como a perspectiva central de atenção à vida. Isto não quer dizer que devemos adotar a postura ingênua de abandono da técnica [6], pelo contrário, trata-se aqui de usá-la conscientemente para que a assombrosa memória contemplativa de Funes e a do implante Willow Grainexistam apenas no terreno ficcional. Nós devemos, ao invés, nos questionar: Para que produzimos tantos arquivos? Para quem? Para quando?

Cabe investigar, portanto,não apenas o papel dessa nova ecologia midiática nos modos de funcionamento da memória social na contemporaneidade, isto é, como guardamos e como recuperamos informação, e suas implicações, mas também o modo como interagimos com essa nova experiência de memória mediatizada em rede. Trata-se de um rememorar que, embora desprovido da pulsação natural da memória, sempre retorna sintomaticamente. Não à toa, Hoskins (2015, p. 18) sugere a criação de uma sociologia das assombrações que se encarregue de seguir os restos e os rastros do arquivo digital. É precisamente na aridez dos bancos de dados que a pesquisa sobre a memória digital encontra meios de fertilizar-se.

\section{Notas}

[1] Uma ficção especulativa, atualmente na quinta temporada, que recentemente passou a ser produzida pelo serviço de streaming Netflix. A premissa da série consiste em apontar as consequências imprevistas, e por vezes distópicas, no uso das tecnologias; a cada episódio surgem não apenas "realidades" mas também avanços tecnológicos próprios, uns mais outros menos próximos dos nossos, que criam os futuros nem tão distantes da odisseia da técnica como ex- 
tensão do humano.

[2] Se, como observa Derrida (2001), o arquivo é uma resposta e uma responsabilidade com o amanhã, resta-nos apenas arquivar ainda mais e conjecturar sobre o modo como as gerações futuras irão selecionar e analisar a imensidão documental de nossa época.

[3] Embora seja possível apagar algumas memórias, vemos no episódio que tal ação não é bem vista socialmente, isto porque numa sociedade transparente como essa, na qual o implante serve como uma espécie de ID universal, isto é sinônimo de que algo grave está sendo escondido. No caso, o dado é apagado, mas o rastro daquilo que foi deletado permanece como índice do acontecido.

[4] Nessa realidade em que a memória técnica é valorizada em detrimento da memória natural, a fala da desenvolvedora da tecnologia Willow Grain é sintomática dentro dessa cultura; ela argumenta, diante de uma personagem que teve o implante roubado e optou por não recolocá-lo, que boa parte da memória orgânica é composta por lixo, além de não ser confiável, já que pode ser manipulada pela implantação de falsas memórias.

[5] A fotografia talvez tenha sido o primeiro passo para que a técnica se apoderasse do instante vivido como um signo para a lembrança voluntária ao petrificar em seu negativo apenas esparsos momentos de todo o horizonte da vivência atual.

[6] De fato, Bernard Stiegler (2010, p. 67) considera que a memória humana se confunde com a técnica desde o seu início na medida em que recorre a suportes exteriores, passando pelas mnemotécnicas de conservação como a escrita e os palácios de memória até chegar às mnemotecnologias contemporâneas. Seja qual for o suporte, seu caráter técnico se destaca por um esforço de conservação, bem como de ordenação dessa matéria que compõe a memória.

\section{Referências}

BENJAMIN, Walter. Der Erzähler. In: GesammelteSchriftenv. II. Frankfurt am Main: SuhrkampVerlag, 1977.

. Charles Baudelaire:EinLyrikerimZeitalter des Hochkapitalismus. In: GesammelteSchriften v. I. Frankfurt am Main: SuhrkampVerlag, 1974.

BERGSON, Henri. Matéria e memória: ensaio sobre a relação do corpo com o espírito. São Paulo: Martins Fontes, 1999.

BORGES, Jorge Luis. Funes el memorioso. In: . Ficciones. Madrid: Alianza, 1981.

COLOMBO, Fausto. Os arquivos imperfeitos: memória social e cultura eletrônica. São Paulo: Editora Perspectiva, 1991.

DELEUZE, Gilles. Le bergsonisme. Paris: PUF, 1966.

DERRIDA, Jacques. Mal de arquivo: uma impressão freudiana. Rio de Janeiro: RelumeDumará, 2001.

FREUD, Sigmund. VorlesungenzurEinführung in die Psychoanalyse und NeueFolge. Frankfurt am Main: Fischer, 1969 (Studienausgabe v. I).

GOFFMAN, Erving. The presentation of self in everyday life. London: Penguin Books, 1990.

GUMBRECHT, Hans Ulrich. Production of presence: what meaning cannot convey. 
Stanford: Stanford University Press, 2004.

HALBWACHS, Maurice. A memória coletiva. São Paulo, Centauro, 2006.

HOSKINS, Andrew. Archive Me! Media, memory, uncertainty. In: HAJEK, Andrea et al. Memory in a Mediated World: remembrance and reconstruction. Basingstoke: Palgrave Macmillan, 2015.

HUYSSEN, Andreas. Passados presentes: mídia, política e amnésia. In: Seduzidos pela memória: arquitetura, monumentos, mídia. Rio de Janeiro: Aeroplano, 2000.

NORA, Pierre. Entre memória e História: a problemática dos lugares. Projeto História, São Paulo, n. 10, dez. 1993.

POLLAK, Michael. Memória e identidade social. Estudos Históricos. Rio de Janeiro, v. 5, n.10, 1992.

REISZ, Barney; WELSH, Brian. The entire history of you. [Série televisiva-vídeo]. Produção de Barney Reisz, direção de Brian Welsh. United Kingdom: Endemol UK, 2011 (44 min). color. son.

RICOEUR, Paul. A memória, a história, o esquecimento. Campinas: Editora da Unicamp, 2007.

SARLO, Beatriz. Tempo passado: cultura da memória e guinada subjetiva. São Paulo: Companhia das Letras, 2007.

STIEGLER, Bernard. Memory. In: MITCHELL, W. J. T.; GUMBRECHT, Hans Ulrich. Critical terms for media studies. Chicago: University of Chicago Press, 2010. 